\title{
Investigation of the Regio- and Stereo- Selectivity of Deoxyguanosine Linkage to Deuterated 2-Hydroxyestradiol by Using Liquid Chromatography/ESI-Ion Trap Mass Spectrometry
}

\author{
L. Debrauwer, E. Rathahao, I. Jouanin, and A. Paris \\ Laboratoire des Xénobiotiques, INRA-ENSAT-ENV, Toulouse, France
}

G. Clodic

Laboratoire d'Enseignement des Méthodes Physico-Chimiques et Analytiques, University P. and M. Curie, Paris, France

\author{
H. Molines \\ Laboratoire des Chimie des Hétérocycles, University P. and M. Curie, Paris, France \\ O. Convert, F. Fournier, and J. C. Tabet \\ Laboratoire des Chimie Structurale Organique et Biologique, University P. and M. Curie, Paris, France
}

From previous studies on the reactivity of estradiol 2,3-quinone towards deoxyribonucleosides, it was demonstrated that several isomeric adducts were formed. Although adduction on steroid ring $\mathrm{A}$ or $\mathrm{B}$ has been evidenced using sequential $\mathrm{MS}^{\mathrm{n}}$ experiments, in some cases attachment positions are difficult to identify unambiguously. In this work, 2-hydroxyestradiol labeled with deuterium at various positions $[6 \beta(1) ; 6 \alpha-7 \alpha(2) ; 6 \alpha-6 \beta-7 \alpha(3)]$ have been used. Isomeric adduct differentiation could be achieved using LC-ESI-MS ${ }^{\mathrm{n}}$. The $\mathrm{m} / \mathrm{z}$ shift of the quasi-molecular ions as well as the fragmentation pathways suggested that adduction could occur on both C6 and C9 sites of the steroid B ring: Nucleophilic attack of the base on the C6 position of the steroid led to major adducts and addition of the base on the activated C9 site gave minor adducts that were found to be unstable. LC-MS ${ }^{\mathrm{n}}$ experiments carried out under deuterated medium provided information about some fragmentation processes by studying the $\mathrm{m} / \mathrm{z}$ shift of fragment ions: (1) the loss of deoxyribose from the quasi-molecular ions took place according to a process involving a deuterium transfer from the deoxyribose alcohol function; (2) the cleavage of the steroid-base linkage involved a deuterium transfer from the hydroxy group of the catechol and likely occurred via the formation of an ion-dipole complex. The model studies conducted in this work provide new information on the fragmentation mechanisms of covalent adducts formed from estrogen quinones and deoxyguanosine, the most reactive DNA base. Besides, the first unequivocal characterization of adducts involving the steroid C9 position is shown by using deuterium labeled estrogen quinones. (J Am Soc Mass Spectrom 2003, 14, 364-372) (c 2003 American Society for Mass Spectrometry

$\mathrm{T}$ The enzymatic hydroxylation of the aromatic A ring of estrogens via cytochrome P450 enzymes leading to catechol estrogens represents one of the major metabolic pathways of estrogens [1-3]. Catechol estrogens are mainly inactivated by conversion into their O-methylated [4] or glucuronide and sulfate

Published online March 14, 2003

Address reprint requests to Dr. L. Debrauwer, UMR 1089 Xénobiotiques, INRA-ENSAT-ENV, 180 chemin de Tournefeuille, B.P. 3, 31931 TOULOUSE Cedex 9, France. E-mail: laurent.debrauwer@toulouse.inra.fr conjugated forms [5]. If those preventive pathways are not completed, catechol estrogens can undergo further metabolic activation steps to quinones, highly electrophilic species that can covalently bind to nucleophilic groups, via Michael addition reactions [2, 6-8]. In particular, the adduction of catechol estrogens to DNA bases $[2,7,8]$ is known to induce mutations $[9,10]$ that may initiate cancer $[1,2]$. The major protective pathway against this process is the reaction with glutathione [4, 11-13] yielding conjugates which can be easily excreted. The reactions of estradiol-3,4-quinone with deoxyribo- 
nucleosides have been extensively studied [8, 14-16] and the major covalent adduct formed from model reactions was detected in vivo from rats [17] or hamsters [18] treated with 4-hydroxyestradiol.

The occurrence of DNA adducts can be evidenced with great sensitivity using immunoassays and ${ }^{32} \mathrm{P}$ post-labelling [7, 19], but these methods cannot provide structural information. Because of its sensitivity and specificity, mass spectrometry appears to be a powerful tool for exploring this field of investigation [20-22]. Moreover, the possibility of on-line coupling with separation techniques, such as HPLC or CE, enhances the detection capabilities of this method [23-25]. Among different soft desorption-ionization techniques (e.g., MALDI, FAB, TSP), electrospray ionization is now commonly used for DNA adduct analysis, because of the very soft desolvation conditions which avoid fragile bond cleavages. Although negative ESI is widely used for the analysis of unmodified [26, 27] as well as modified oligonucleotides [28-30], the adducts formed between nucleosides and electrophilic reagents are generally analyzed using positive ionization [31-33], mainly for better sensitivity reasons. In previous works [34], the resulting products from the reactivity of estradiol-2,3-quinone towards desoxyribonucleosides have been investi-

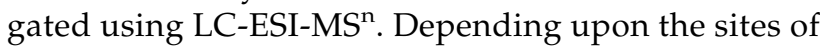
both the DNA base and the steroid involved in the Michael addition process, several isomeric compounds were formed, in particular with $\mathrm{dG}$ which was found to be the most reactive deoxyribonucleoside $[8,34]$. Regio- and stereo-isomeric adducts have been identified using concomitant LC-ESI/MS ${ }^{n}$ and NMR methodologies [35]. Although the use of sequential LC-MS ${ }^{n}$ experiments allowed to determine the regiochemistry of adduction (e.g., at the A or B ring of the steroid), in some cases, the linkage position could not be clearly evidenced. In this context, studies using labeled compounds with deuterium atoms at various sites have been undertaken in order to highlight the differentiation of isomeric adducts by studying the mass shift and the fragmentation pattern of their corresponding quasi-molecular ions, thus providing additional information on the adduction site.

In the present work, deuterium labeled 2-hydroxy$17 \beta$-estradiol $\left(2 \mathrm{OHE}_{2} \beta\right)$ [i.e., $6 \beta$ (1); $6 \alpha-7 \alpha(2) ; 6 \alpha-6 \beta-7 \alpha$ (3)] have been synthesized (Scheme 1). The corresponding labeled quinones have been formed and let to react with deoxyguanosine. The resulting crude mixtures were directly analyzed by LC-ESI-MS ${ }^{\mathrm{n}}$ using previously developed analytical conditions [34]. Various LC-MS ${ }^{2}$ and LC-MS ${ }^{3}$ experiments into an ion trap have been performed via resonant excitation of the different selected ions. LC-MS ${ }^{n}$ experiments using deuterated mobile phases have also been carried out in order to clarify some fragmentation processes.

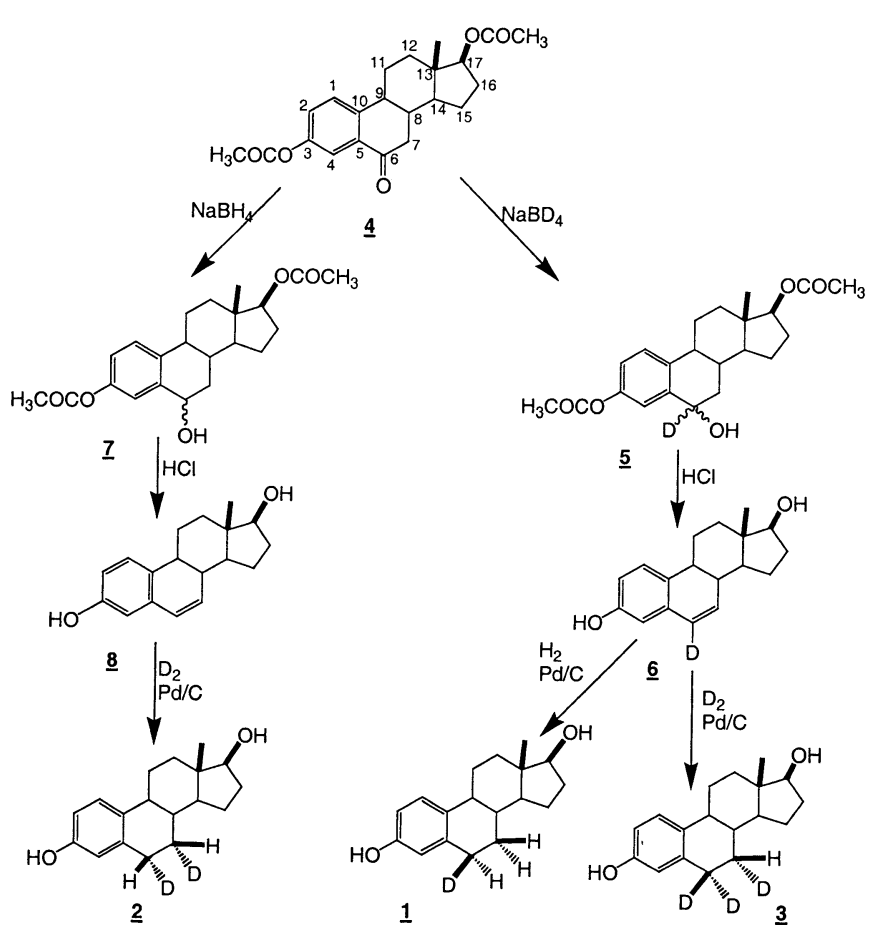

Scheme 1. Synthesis of deuterium labeled estradiol.

\section{Experimental}

\section{Mass Spectrometry}

All experiments were performed on a Finnigan LCQ ion trap mass spectrometer (Thermo Quest, Les Ulis, France) equipped with an ESI source operated in the positive mode using the following conditions: Needle voltage $(5 \mathrm{kV})$; heated capillary temperature $\left(230^{\circ} \mathrm{C}\right)$; capillary voltage $(4 \mathrm{~V})$; tube lens offset $(5 \mathrm{~V})$. Nitrogen was used as the sheath gas at a flow rate of $80 \%$ (arb. units). All spectra were acquired using AGC (Automatic Gain Control). MS $^{\mathrm{n}}$ experiments were carried out using $\mathrm{He}$ as collision gas. Collision energies were adjusted in order to get maximum structural information for each experiment, i.e., typically $17-20 \%$ for MS/MS on the quasi-molecular species, and $21 \%$ for $\mathrm{MS}^{3}$ experiments $(100 \%$ collision energy corresponds to $5 \mathrm{~V}$ peak to peak). In all $\mathrm{MS}^{\mathrm{n}}$ experiments, ions were isolated at $\mathrm{q}_{\mathrm{z}} 0.83$ with $1.5 \mathrm{u}$ as ion isolation width and excited at $\mathrm{q}_{\mathrm{z}} 0.25$.

\section{Liquid Chromatography}

Liquid chromatography has been used to introduce the samples into the ESI source at a $0.2 \mathrm{ml} / \mathrm{min}$ flow rate. This was carried out using a Thermo Separation P4000 pump (Thermo Quest) fitted with a Rheodyne injector. The LC column used was an Ultrabase $5 \mu \mathrm{m}$ C18 column $(25 \times 2 \mathrm{~mm})$ from SFCC (Eragny, France). The following gradient elution was used: $100 \%$ A to $85 \%$ A from 0 to $5 \mathrm{~min}$., then $85 \%$ A to $50 \%$ A from 5 to $30 \mathrm{~min}$., and $50 \%$ A to $100 \% \mathrm{~B}$ from 30 to $40 \mathrm{~min}$., and finally $100 \% \mathrm{~B}$ from 40 to 60 min., with $\mathrm{A}, \mathrm{H}_{2} \mathrm{O} / \mathrm{CH}_{3} \mathrm{OH} /$ 
Table 1. Isomeric adducts obtained from reactions of deuterium labeled steroids 1, 2, 3 with dG.

\begin{tabular}{|c|c|c|c|}
\hline Adducts M W & (1) + dG 554 & (2) + dG 555 & (3) + dG 556 \\
\hline Isomers & $\mathbf{b}^{\mathrm{b}}$ & $\mathbf{b}^{\mathrm{b}}$ & $a^{a}$ \\
\hline Quasi-molecular ions $\mathrm{m} / \mathrm{z}$ & $\begin{array}{l}555\left(\mathrm{M}_{\mathrm{d} 1} \mathrm{H}^{+}, 75 \%\right) \\
554\left(\mathrm{M}_{\mathrm{d} 0} \mathrm{H}^{+}, 25 \%\right)\end{array}$ & $\begin{array}{l}556\left(\mathrm{M}_{\mathrm{d} 2} \mathrm{H}^{+}, 75 \%\right) \\
555\left(\mathrm{M}_{\mathrm{d} 1} \mathrm{H}^{+}, 25 \%\right)\end{array}$ & $\begin{array}{l}557\left(\mathrm{M}_{\mathrm{d} 3} \mathrm{H}^{+}, 20 \%\right) \\
556\left(\mathrm{M}_{\mathrm{d} 2} \mathrm{H}^{+}, 80 \%\right)\end{array}$ \\
\hline
\end{tabular}

aretention time: $30.4 \mathrm{~min}$

bretention time: $31.6 \mathrm{~min}$

\section{$\mathrm{CH}_{3} \mathrm{COOH}(90: 10: 0.2)$ and $\mathrm{B}, \mathrm{H}_{2} \mathrm{O} / \mathrm{CH}_{3} \mathrm{OH} / \mathrm{CH}_{3} \mathrm{COOH}$ (10:90:0.2).}

\section{Materials}

The synthetic procedure used for the preparation of the studied adducts from the different deuterated compounds was described in the literature [8]. Briefly, the 2-hydroxy derivatives of the deuterated compounds were prepared according to the method described by Gelbke et al. [36]. The deuterated quinones were prepared by oxidation in acetonitrile at $-40{ }^{\circ} \mathrm{C}$ of the corresponding catechols using activated manganese dioxide utilizing a procedure published by Abul-Hajj et al. [37]. The resulting suspension was then filtered directly into a stirred solution of $\mathrm{dG}$ as previously described [8] and let to react $5 \mathrm{~h}$ at room temperature.

Compounds 1, 2, 3 were prepared from the 6-keto$17 \beta$-estradiol diacetate 4 (Scheme 1). 4 was prepared from $17 \beta$-estradiol as described by Garza and Rao [38] and reduced with sodium borohydride (deuterated or not) to give the alcohols 5 or 7 . These products were dehydrated to give the Compounds 6 or $\mathbf{8}$, which were then hydrogenated on $\mathrm{Pd} / \mathrm{C}$ as catalyst either with hydrogen or with deuterium gas. The stereochemistry of all the deuterated compounds was checked by comparison of the corresponding ${ }^{1} \mathrm{H}$ NMR spectra with that of $17 \beta$-estradiol.

Synthesis of compounds 1 and 3. A solution of 4 (100 mg) in $3.3 \mathrm{~mL}$ of methanol- $d_{4}$-tetrahydrofuran- $d_{8}(10: 1, \mathrm{vol} /$ vol) was stirred at $-15{ }^{\circ} \mathrm{C}$ with sodium borohydride- $d_{4}$ for $30 \mathrm{~min}$. Acetic acid $(0.15 \mathrm{~mL})$ was added and the mixture stirred for $85 \mathrm{~min}$. After addition of water (50 $\mathrm{mL})$, extraction with ethylacetate and drying over magnesium sulfate, $6-{ }^{2} \mathrm{H}-6$-hydroxy- $17 \beta$-estradiol diacetate (5) was obtained ( $46 \%$ yield).

A methanolic solution of 5 (12 $\mathrm{mg}$ in $12 \mathrm{~mL})$ was stirred for $8 \mathrm{~h}$ with $1 \mathrm{~N} \mathrm{HCl}(8 \mathrm{~mL})$, then for $15 \mathrm{~h}$ more with $1 \mathrm{~N} \mathrm{HCl}(4 \mathrm{~mL})$. After methanol evaporation, washing with water, extraction with ethylacetate, and drying over magnesium sulfate, $41 \mathrm{mg}$ of deuterated Compound 6 were obtained ( $47 \%$ yield). A solution of $30 \mathrm{mg}$ of 6 in a mixture of $8 \mathrm{mg} 10 \% \mathrm{Pd} / \mathrm{C}$ in ethylacetate $(2 \mathrm{~mL})$ was hydrogenated with $\mathrm{D}_{2}$ at atmospheric pressure to give the Compound 3 after filtration and evaporation. A similar procedure with $\mathrm{H}_{2}$ led to the Compound 1.

$6 \beta-{ }^{2} \mathrm{H}-17 \beta$-estradiol (1): ${ }^{1} \mathrm{H}$ NMR (in $\mathrm{CD}_{3} \mathrm{OD}$ ), $\delta 0.77$ (s, 3H, $\left.\mathrm{CH}_{3}\right), 1.14\left(\mathrm{~m}, 1 \mathrm{H}, \mathrm{H}_{14 \alpha}\right), 1.2-1.55\left(\mathrm{~m}, 6 \mathrm{H}, \mathrm{H}_{12 \alpha}\right.$ $\left.\mathrm{H}_{7 \alpha}, \mathrm{H}_{15 \beta}, \mathrm{H}_{8 \beta}, \mathrm{H}_{11 \beta}, \mathrm{H}_{16 \beta}\right), 1.65\left(\mathrm{~m}, 1 \mathrm{H}, \mathrm{H}_{15 \alpha}\right), 1.84(\mathrm{~d}$, $\left.1 \mathrm{H}, \mathrm{H}_{7 \beta}\right), 1.92\left(\mathrm{dt}, 1 \mathrm{H}, \mathrm{H}_{12 \beta}\right), 2.0\left(\mathrm{~m}, 1 \mathrm{H}, \mathrm{H}_{16 \alpha}\right), 2.10(\mathrm{td}$, $\left.1 \mathrm{H}, \mathrm{H}_{9}\right), 2.25\left(\mathrm{dq}, 1 \mathrm{H}, \mathrm{H}_{11 \alpha}\right), 2.75\left(\mathrm{~d}, \mathrm{~J}=5.5,1 \mathrm{H}, \mathrm{H}_{6 \alpha}\right), 3.62$ $\left(\mathrm{t}, 1 \mathrm{H}, \mathrm{H}_{17 \alpha}\right), 6.47\left(\mathrm{~s}, 1 \mathrm{H}, \mathrm{H}_{4}\right), 6.53\left(\mathrm{~d}, 1 \mathrm{H}, \mathrm{H}_{2}\right), 7.06(\mathrm{~d}$, $\left.1 \mathrm{H}, \mathrm{H}_{1}\right)$.

6,6,7 $\alpha-{ }^{2} \mathrm{H}-17 \beta$-estradiol (3): ${ }^{1} \mathrm{H}$ NMR (in $\mathrm{CD}_{3} \mathrm{OD}$ ), $\delta$ $0.77\left(\mathrm{~s}, 3 \mathrm{H}, \mathrm{CH}_{3}\right), 1.14\left(\mathrm{~m}, 1 \mathrm{H}, \mathrm{H}_{14 \alpha}\right), 1.2-1.55(\mathrm{~m}, 6 \mathrm{H}$, $\left.\mathrm{H}_{12 \alpha}, \mathrm{H}_{7 \alpha}, \mathrm{H}_{15 \beta}, \mathrm{H}_{8 \beta}, \mathrm{H}_{11 \beta}, \mathrm{H}_{16 \beta}\right), 1.65$ (m, $\left.1 \mathrm{H}, \mathrm{H}_{15 \alpha}\right), 1.84$ $\left(\mathrm{s}, 1 \mathrm{H}, \mathrm{H}_{7 \beta}\right), 1.92\left(\mathrm{dt}, 1 \mathrm{H}, \mathrm{H}_{12 \beta}\right), 2.0\left(\mathrm{~m}, 1 \mathrm{H}, \mathrm{H}_{16 \alpha}\right), 2.10$ $\left(\mathrm{td}, 1 \mathrm{H}, \mathrm{H}_{9}\right), 2.25\left(\mathrm{dq}, 1 \mathrm{H}, \mathrm{H}_{11 \alpha}\right), 3.62\left(\mathrm{t}, 1 \mathrm{H}, \mathrm{H}_{17 \alpha}\right), 6.47$ $\left(\mathrm{s}, 1 \mathrm{H}, \mathrm{H}_{4}\right), 6.53\left(\mathrm{~d}, 1 \mathrm{H}, \mathrm{H}_{2}\right), 7.06\left(\mathrm{~d}, 1 \mathrm{H}, \mathrm{H}_{1}\right)$.

Synthesis of compound 2. $100 \mathrm{mg}$ of 4 in methanol (4 $\mathrm{mL})$ and tetrahydrofuran $(1 \mathrm{~mL})$ were slowly added to a solution of sodium borohydride $(70 \mathrm{mg}$ in $0.1 \mathrm{~mL}$ water) at $0{ }^{\circ} \mathrm{C}$. This mixture was stirred at $0{ }^{\circ} \mathrm{C}$ for 30 min and $1 \mathrm{~h}$ more after addition of acetic acid $(0.1 \mathrm{~mL})$. After extraction, washing and drying, the crude product was purified on silica plates: $65 \mathrm{mg}$ of solid 6-hydroxy-17 $\beta$-estradiol diacetate 7 were obtained $(65 \%$ yield). A mixture of $38 \mathrm{mg}$ of 7 in methanol ( $5 \mathrm{~mL})$ and $1 \mathrm{~N} \mathrm{HCl}(0.7 \mathrm{~mL})$ was stirred at $80^{\circ} \mathrm{C}$ for $3 \mathrm{~h}$. Then water $(20 \mathrm{~mL})$ was added. After extraction, neutralization, drying, and purification on silica plates, $14 \mathrm{mg}$ of the unsaturated Compound 8 were obtained (51\% yield). As described above, catalytic hydrogenation with $\mathrm{D}_{2}$ on 8 led to the $6,7-{ }^{2} \mathrm{H}-17 \beta$-estradiol 2 with a $45 \%$ yield. The $\mathrm{H}_{2}$ or $\mathrm{D}_{2}$ addition proceeds on the $\alpha$ face.

$6 \alpha, 7 \alpha-{ }^{2} \mathrm{H}-17 \beta$-estradiol (2): ${ }^{1} \mathrm{H}$ NMR (in $\mathrm{CD}_{3} \mathrm{OD}$ ), $\delta$ $0.77\left(\mathrm{~s}, 3 \mathrm{H}, \mathrm{CH}_{3}\right), 1.14\left(\mathrm{~m}, 1 \mathrm{H}, \mathrm{H}_{14 \alpha}\right), 1.2-1.55(\mathrm{~m}, 6 \mathrm{H}$, $\left.\mathrm{H}_{12 \alpha}, \mathrm{H}_{7 \alpha}, \mathrm{H}_{15 \beta}, \mathrm{H}_{8 \beta}, \mathrm{H}_{11 \beta}, \mathrm{H}_{16 \beta}\right), .1 .65\left(\mathrm{~m}, 1 \mathrm{H}, \mathrm{H}_{15 \alpha}\right), 1.84$ $\left(\mathrm{dd}, 1 \mathrm{H}, \mathrm{H}_{7 \beta}\right), 1.92\left(\mathrm{dt}, 1 \mathrm{H}, \mathrm{H}_{12 \beta}\right), 2.0\left(\mathrm{~m}, 1 \mathrm{H}, \mathrm{H}_{16 \alpha}\right), 2.10$ $\left(\mathrm{td}, 1 \mathrm{H}, \mathrm{H}_{9}\right), 2.25\left(\mathrm{dq}, 1 \mathrm{H}, \mathrm{H}_{11 \alpha}\right), 2.75\left(\mathrm{~d}, \mathrm{~J}=5.0,1 \mathrm{H}, \mathrm{H}_{6 \beta}\right)$, $3.62\left(\mathrm{t}, 1 \mathrm{H}, \mathrm{H}_{17 \alpha}\right), 6.47\left(\mathrm{~s}, 1 \mathrm{H}, \mathrm{H}_{4}\right), 6.53\left(\mathrm{~d}, 1 \mathrm{H}, \mathrm{H}_{2}\right), 7.06$ $\left(\mathrm{d}, 1 \mathrm{H}, \mathrm{H}_{1}\right)$.

\section{Results and Discussion}

\section{Labeled Covalent Adducts Molecular Weights}

LC-ESI-MS analyses of the different crude reaction mixtures revealed several isomeric adducts eluted at two different retention times, i.e., 30.4 and $31.6 \mathrm{~min}$, and reported as $\mathbf{a}$ and $\mathbf{b}$ isomers in Table 1, together with their respective molecular weight and the $\mathrm{m} / \mathrm{z}$ of their labeled protonated molecular species. As shown in Table 1, each chromatographic peak consisted of a mixture of isotopomers as indicated by the isotopic 


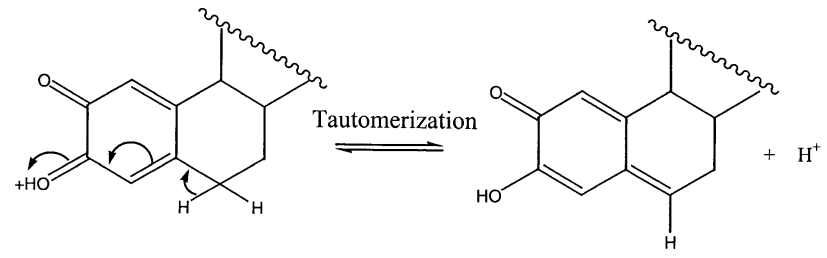

Scheme 2. Proposed mechanism for the isomerization of the $o$-quinone to the $p$-quinone methide.

patterns of the quasi-molecular species. It must be noted that unstable adducts (without deoxyribose moiety) were not observed in our work in contrast with previously published results [34]. This was very likely due to the low yield of the reactions conducted in our study.

First, the direct molecular weight measurement of the various labeled covalent adducts provided information on the attachment position of the nucleoside and steroid partners (Table 1). As previously emphasized [8, 34], almost all adducts were formed by a nucleophilic attack of the deoxyguanosine at the C6 position of the steroid substrate. This suggested that o-quinones isomerized into more electrophilic p-quinone methide forms, which underwent Michael addition reactions with deoxyguanosine, thus resulting in benzylic adducts (Scheme 2). In a similar way, the formation of adducts between quinones and glutathione was also shown to involve such isomerization processes [39-42]. Thus, by analogy with a previously reported basecatalyzed isomerization process [41], a mechanism involving acidic catalysis can be proposed for the formation of covalent adducts between estradiol-2,3-quinone and deoxyguanosine in the acidic medium used in this work (Scheme 2).

The reaction of deuterium labeled steroids led to covalent adducts displaying shifted $\mathrm{m} / \mathrm{z}$ of the quasimolecular species. As indicated in Table 1, major adducts were detected at $\mathrm{m} / \mathrm{z} 556$ from both 2 and 3 isotopomers and at $m / z 555$ from 1. This indicated one deuterium atom $(\mathrm{C} 6 \alpha / \beta$ or $\mathrm{C} 7 \alpha$ position) was lost from 3 whereas the deuterium atoms from $\mathbf{1}$ and $\mathbf{2}$ were preserved. This behavior suggested that the formation of these adducts may involve the elimination of one $\mathrm{H}$ or $\mathrm{D}$ atom from the $\mathrm{C} 6$ position of the steroid $\mathrm{B}$ ring. Indeed, the $m / z$ of the observed quasi-molecular ions depended upon the nature of the atom lost during the oxidation step of the catechol estrogen into its corresponding quinone methide form as described in Scheme 2. The loss of $\mathrm{H}$ at position $\mathrm{C} 6$ from 1 and 2, led to the major isotopomeric covalent adduct ions at $\mathrm{m} / \mathrm{z}$ 555 and 556, respectively. Conversely, the elimination of one $\mathrm{D}$ at position $\mathrm{C} 6 \beta$ for $\mathbf{1}$ and $\mathrm{C} 6 \alpha$ for $\mathbf{2}$ observed as a minor process led to the occurrence of ions at $m / z 554$ and 555. This result indicated that an isotope effect may occur in the formation of the p-quinone methides for $\mathbf{1}$ and $\mathbf{2}$, in which the hydrogen elimination is favored compared to that of the deuterium atom. A similar isotope effect has also been reported for the isomeriza-

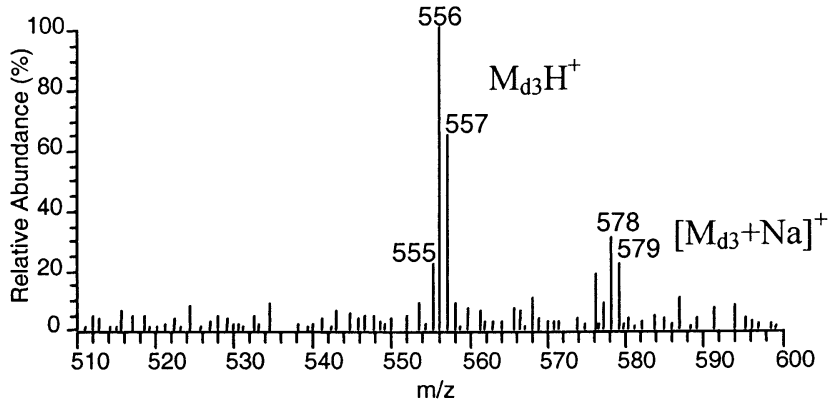

Figure 1. Positive ESI mass spectrum of the $\mathbf{b}$ isomer of $(3+$ $\mathrm{dG})$.

tion of 4-propyl-o-quinone into its tautomeric pquinone methide form [41] and was in the range of $k_{H} / k_{D}=5.5 \pm 0.6$ at $37^{\circ} \mathrm{C}$.

On the other hand, the presence of some adducts detected as the $\mathrm{M}_{\mathrm{d} 3} \mathrm{H}^{+}$ions at $m / z 557$ (and $\left[\mathrm{M}_{\mathrm{d} 3}+\mathrm{Na}\right]^{+}$ ions at $m / z 579$ ) from 3 indicated that the initial labeling could also be preserved on the trideuterated compound (Figure 1). Hence, in this case, a base addition occurring at a site other than the C6 position (i.e., at the C9 position or the A ring) had to be considered.

\section{$M S^{n}$ Experiments on the $\mathrm{m} / \mathrm{z} 555$ and 556 Ions} from 1, 2, and 3

As indicated on Figure $2 \mathrm{a}, \mathrm{b}$, and $\mathrm{c}$, all the ionic adduct species (a isomers as well as $\mathbf{b}$ isomers) at $m / z 555$ and 556 ion decomposed according to the same fragmentation pathway. This fragmentation mainly involved the loss of the deoxyribose moiety from the quasi-molecular ions in the $\mathrm{MS}^{2}$ step, whereas the resulting fragment ion underwent the cleavage of the steroid-base bond leading to the formation of the protonated base $(\mathrm{m} / \mathrm{z}$ 152) and $[\mathrm{MH}-\mathrm{dG}]^{+}(\mathrm{m} / \mathrm{z} 288$ or 289) as a pair of complementary ions. However, slight differences can be observed on the CID spectrum of 1 (Figure 2a) when compared to the CID spectra of 2 and 3 (Figure $2 b$ and c), concerning in particular the stability of the molecular species. Indeed, when submitted to the same isolation and excitation conditions in the ion trap cell, the $1 \mathrm{H}^{+}$ species seems to be more stable than its $2 \mathrm{H}^{+}$and $3 \mathrm{H}^{+}$ counterparts. This difference may be due to isotope effects, which seem difficult to interpret. However, the subsequent $\mathrm{MS}^{3}$ spectra acquired from the $\mathrm{m} / \mathrm{z} 440$ (or 439) daughter ions are completely identical for 1 (Figure 2a), 2 (Figure 2b), and 3 (Figure 2c). This shows that these $m / z 440$ (or 439 ) selected product ions are the same ionic species. These results were consistent with the attachment of the base at the steroid B ring and indicated that all the adduct ions ( $\mathbf{a}$ and $\mathbf{b}$ isotopomers), possessed similar structures. As already reported [8], nucleophilic attack at the prochiral $\mathrm{C} 6$ atom of the steroid resulted in the formation of two diastereoisomers ( $\mathbf{a}$ and $\mathbf{b}$ isomers) which corresponded to the $\alpha$ and $\beta$ forms as illustrated in Scheme 3 on the basis of Compound 3 . The formation of the quinone methide 
(a)
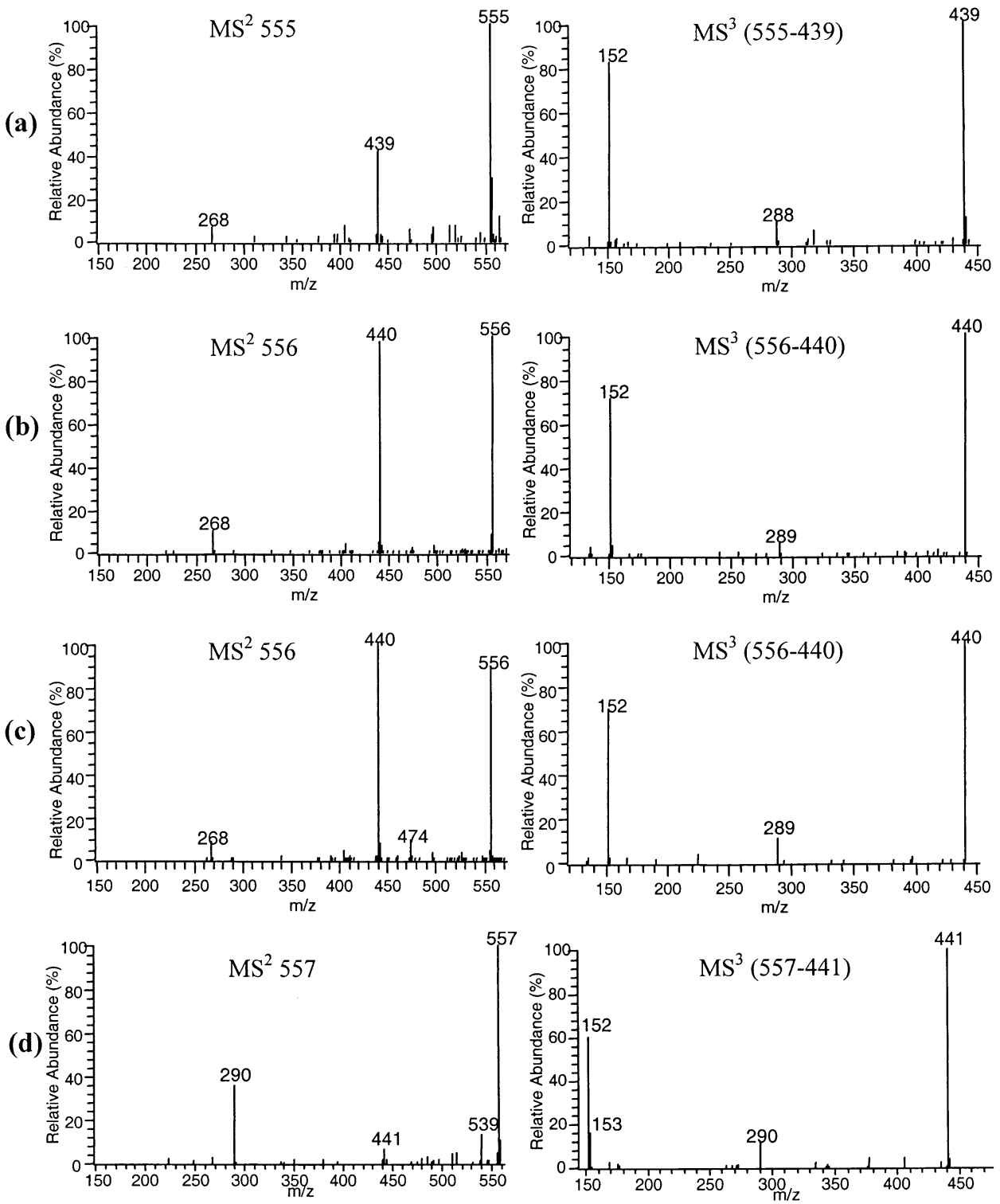

Figure 2. $\mathrm{MS}^{2}$ and $\mathrm{MS}^{3}$ spectra of ESI-produced protonated molecular ions from the $\mathbf{b}$ isomer of (a) $(\mathbf{1}+\mathrm{dG}),(\mathbf{b})(\mathbf{2}+\mathrm{dG})$, and $(\mathbf{c}$ and $\mathbf{d})(\mathbf{3}+\mathrm{dG})$.

intermediate implies a loss of stereochemistry at the C6 position of the steroid as reported in Scheme 2, accompanied by an isotope effect concerning the $\mathrm{H}$ or $\mathrm{D}$ elimination. This explains the occurrence of isotopomers at $\mathrm{M}$ and $\mathrm{M}+1$ on both diastereoisomers formed according to Michael addition processes. Such isomeric adduct species have already been evidenced by LC-ESI-MS/MS and NMR and it has been shown that both diastereoisomers could be separated by HPLC $[34,35]$.

$M S^{n}$ Experiments on the $\mathrm{m} / \mathrm{z} 557$ Ions from 3: Evidence for a Reaction at the Steroid C9 Position

The $\mathrm{m} / \mathrm{z} 557$ ions from the labeled Compound 3 possessed a significant relative abundance $(65 \%$ of the peak $m / z 556$, see Figure 1). In this case, the contribution of the ${ }^{13} \mathrm{C}$ natural isotopic abundance of the $m / z 556$ ions, and the occurrence of covalent adducts which preserved the three initial D atoms should be considered. Taking into account that the natural isotopic contributions at $\mathrm{M}+1$ for a $\mathrm{C}_{28} \mathrm{H}_{35} \mathrm{O}_{7} \mathrm{~N}_{5}$ species, the relative abundance of the peak at $\mathrm{m} / \mathrm{z} 557$ should correspond to ca. $33 \%$ of the protonated ions at $m / z 556$. The actual relative abundance observed for the $\mathrm{m} / \mathrm{z} 557$ ion is $65 \%$. The same trend is observed for the $\mathrm{MNa}^{+}$species, with the $\mathrm{m} / \mathrm{z} 579$ ion relative abundance corresponding to $65 \%$ of the peak at $\mathrm{m} / \mathrm{z} 578$ (Figure 1). This indicated that the $\mathrm{m} / \mathrm{z} 557$ ion also contained a molecular species in which the three initial D atoms were preserved, suggesting that the adduction process may also occur on a site other than the C6 position. Moreover, the CID spectrum presented in Figure $2 \mathrm{~d}$ also showed that the behavior of the $\mathrm{m} / \mathrm{z} 557$ ions from 3 towards collisional 


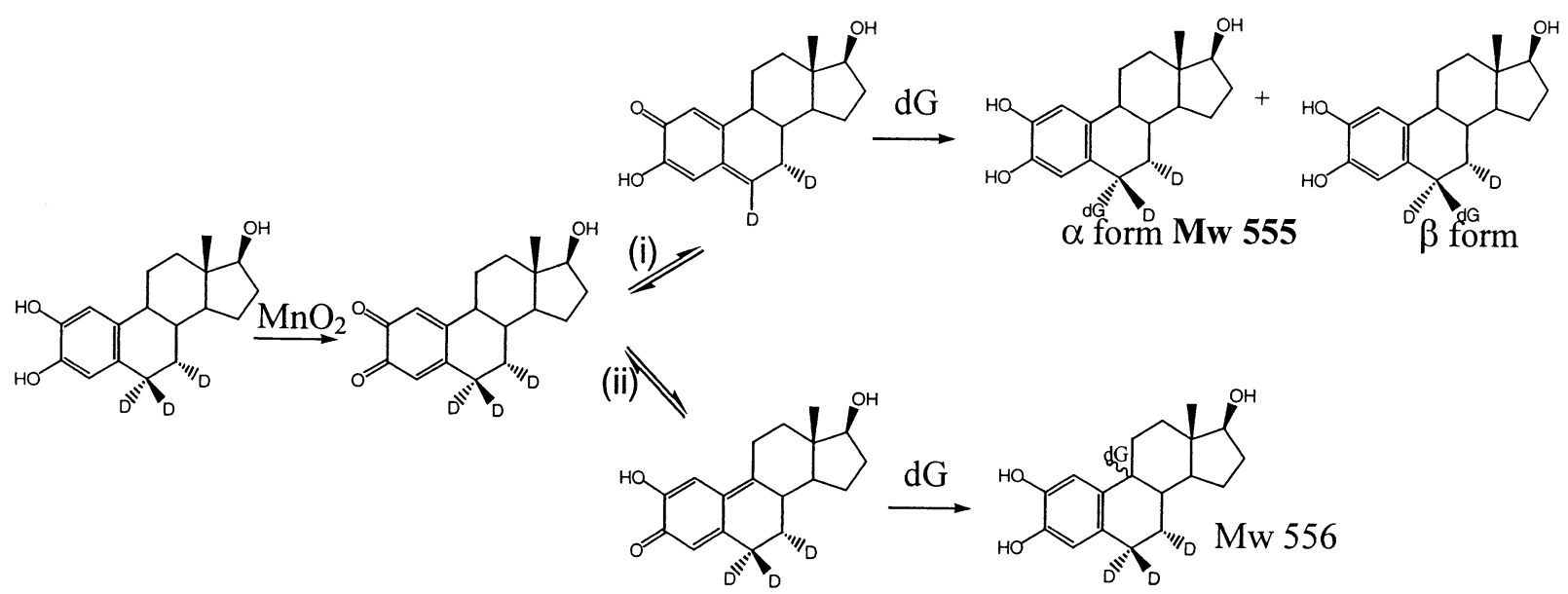

Scheme 3. Proposed reaction pathway for adduct formations in the reaction between 3 and dG.

activation was specific. In this case, the main fragmentation pathways consisted of a water elimination and steroid-base linkage cleavage to yield the $\mathrm{m} / \mathrm{z} 539$ and 290 ions, respectively, whereas the loss of deoxyribose was observed as a weak process. This particular pattern has never been observed on estrogen quinone-deoxyribonucleoside covalent adducts until this work, indicating that this adduct should have a different structure. From previously published results [8], the adduction process at the steroid A ring could be ruled out since the nucleobase and steroid are strongly bonded in such covalent adducts, which mainly dissociate according to charge-remote fragmentations [8, 34, 35]. Moreover, in this case, the presence of both complementary ions at $\mathrm{m} / \mathrm{z} 152$ and 290 in the $\mathrm{MS}^{3}$ spectrum of the [MHdeoxyribose $]^{+} \mathrm{m} / \mathrm{z} 441$ ions (resulting from the decomposition of the parent $\mathrm{m} / \mathrm{z} 557$ ions) was characteristic of the cleavage of the steroid-base linkage, consistent with a linkage at the steroid $\mathrm{B}$ ring. The presence of a weak signal at $m / z 153$ was very likely due to the ${ }^{13} \mathrm{C}$ contribution of the $\mathrm{m} / \mathrm{z} 556$ ions also selected at $\mathrm{m} / \mathrm{z} 557$ and could be attributed to the ${ }^{13} \mathrm{C}$ contribution of the protonated base. Thus, it can be concluded that the $\mathrm{m} / \mathrm{z}$ 557 ions probably correspond to a covalent adduct resulting from the addition of the base on the activated C9 site as reported in Scheme 3. As the C9 site was also a prochiral center, two diastereoisomers could also be expected. However, these C9 attachment adducts detected at $\mathrm{m} / \mathrm{z} 557$ appeared to be eluted at retention times similar to those of the $\mathbf{a}$ and $\mathbf{b}$ isomers of the C6 attachment adducts, respectively. The greater abundance of the $\mathrm{m} / \mathrm{z} 290$ ions relative to the $\mathrm{m} / \mathrm{z} 441$ ions in the $\mathrm{MS}^{2}$ spectrum of the $\mathrm{m} / \mathrm{z} 557$ ions (Figure 2d) could be expected from a C9 adduct since the elimination of the base moiety can be favored because of steric decompression effects and the tertiary character of the produced carbonium site.

The formation of some adduct ions at $m / z 555\left(\mathrm{~d}_{1}\right)$ and $556\left(\mathrm{~d}_{2}\right)$ could also be expected from 1 and 2 , respectively, considering the same nucleophilic attack at the $\mathrm{C} 9$ position of the steroid resulting in the preservation of the initial number of deuterium atoms, but the occurrence of these species could not be evidenced in our experiments.

It can be concluded from these results that the reaction of $\mathrm{dG}$ at the $\mathrm{C} 9$ position led to unstable adducts, which could be evidenced by the specific fragmentation pathway observed from the $\mathrm{m} / \mathrm{z} 557$ ion of $\mathbf{3}$ from freshly prepared reaction mixtures, and which decomposed after several hours. This assumption was further supported by the change in the isotopic profile initially observed (Figure 1) from a $\mathrm{m} / \mathrm{z} 557$ relative intensity of $65 \%$ to a relative intensity below ca. 30\% when the same sample was analyzed some days after. Furthermore, the CID spectrum of the $\mathrm{m} / \mathrm{z} 557$ ions selected from 3 became similar to those of the other quasi-molecular ions described in Figure $2 \mathrm{a}$ to c, i.e., it displayed a major fragment ion at $\mathrm{m} / \mathrm{z} 441$ whereas no diagnostic fragment ions at $\mathrm{m} / \mathrm{z} 290$ and 539 were observed (data not shown). This behavior indicated that after several hours, the C9 attachment adducts were degraded and the detected $\mathrm{m} / \mathrm{z} 557$ ions only corresponded to the ${ }^{13} \mathrm{C}$ isotopic contribution of the $\mathrm{m} / \mathrm{z} 556$ ions formed according to the $\mathrm{C} 6$ addition process.

Although adducts with the C9 attachment had never been clearly evidenced in previous works, a compound identified as the $11-\mathrm{oxo}-2 \mathrm{OHE}_{2} \beta$ was detected in crude reaction mixtures, and its origin was attributed to the degradation of such C9 covalent adducts [35, 43]. Alternatively, the nucleophilic attack at the $\mathrm{C} 9$ position was also proposed for the formation of some estrogen quinone-glutathione adducts, but the occurrence of such species could not be evidenced [39, 42]. In this case, the unstable character of such adducts was also reported and only products formed by elimination of glutathione (i.e., 9-dehydro-4OHE and 9-dehydro-2OHE from 4OHE-o-quinone and 2OHE-o-quinone, respectively) were identified as the end products of the degradation of such transient adduct species [39, 42]. 
Table 2. $\mathrm{m} / \mathrm{z}$ ratios of the various ionic species obtained by LCESI/MSn analyses of crude reaction mixtures in deuterated medium.

\begin{tabular}{|c|c|c|c|c|c|}
\hline Adducts & $\begin{array}{l}\mathrm{M}_{\mathrm{d}} \mathrm{D}^{+} \\
(\mathrm{m} / \mathrm{z})\end{array}$ & & $\begin{array}{c}{\left[\mathrm{M}_{\mathrm{d}} \mathrm{D} \text {-deoxyribose }\right]^{+}} \\
(\mathrm{m} / \mathrm{z})\end{array}$ & & $\begin{array}{l}\mathrm{BD}_{2}^{+} \\
(\mathrm{m} / \mathrm{z})\end{array}$ \\
\hline $2 \mathrm{OHE}_{2} \beta+\mathrm{dG}$ & 562 & $\stackrel{\mathbf{M S}^{2}}{\Rightarrow}$ & 445 & $\stackrel{\mathrm{Ms}^{2}}{\Rightarrow}$ & 157 \\
\hline$(2)+d G$ & 564 & $\mathrm{Ms}^{2}$ & 447 & $\stackrel{\mathrm{Ms}^{2}}{\Rightarrow}$ & 157 \\
\hline$(3)+d G$ & 564 & $\mathrm{Ms}^{2}$ & 447 & $\stackrel{\mathrm{Ms}^{2}}{\longrightarrow}$ & 157 \\
\hline
\end{tabular}

\section{Fragmentation Processes Under $M S^{n}$ Conditions} as Revealed by LC-MS ${ }^{n}$ Analyses in Deuterated Medium

In order to gain complementary information on the covalent adduct fragmentation processes, LC-MS ${ }^{\mathrm{n}}$ analyses have been performed using deuterated mobile phases. The $\mathrm{m} / \mathrm{z}$ of the various ionic species of interest are reported in Table 2. Under these conditions, H/D exchanges occurred in solution and the $\mathrm{m} / \mathrm{z}$ of quasimolecular ions were shifted by $8 \mathrm{Th}$, which is consistent with the occurrence of seven exchangeable hydrogen atoms in the covalent adduct structure and the associated addition of a deuterium for ionization. MS/MS as well as MS $^{3}$ experiments were carried out on these various species (Table 2). The resulting low energy CID spectra of these species mainly displayed product ions at $m / z 445$ from $\left(2 \mathrm{OHE}_{2} \beta+\mathrm{dG}\right)$ and $m / z 447$ ions from $(2+d G)$ or $(3+d G)$, corresponding to the loss of the deoxyribose moiety from the molecular species. Surprisingly, a specific loss of $117 \mathrm{u}$ instead of the expected $118 \mathrm{u}$ loss has been observed for the deoxyribose moiety elimination process. Taking into account the exchangeable hydrogen atoms on the deoxyribose moiety, the formation of these fragment ions by loss of $117 \mathrm{u}$ was unexpected, since the H/D exchanges in the ion trap were minor during the MS/MS experiment period as observed from the fragmentation of protonated standard compounds in deuterated medium (data not shown). Hence, a process involving a deuterium migration from the deoxyribose to the base moiety could explain the $\mathrm{m} / \mathrm{z}$ shift of fragment ions formed by the loss of deshydrogenated deoxyribose from the quasi-molec- ular ions (Scheme 4), although other processes (e.g., formation of an ion-dipole complex followed by H/D exchange) could also rationalize the formation of such species.

From the $\mathrm{MS}^{3}$ experiments carried out on the $m / z 445$ or 447 ions, the $\mathrm{m} / \mathrm{z}$ shift observed for the product protonated base $(\mathrm{m} / \mathrm{z} 152$ to 157$)$ showed that an elimination mechanism involving a hydrogen on $\mathrm{C} 7$ position could be ruled out for the formation of such species. A mechanism involving a D transfer should preferably be considered. Hence, the cleavage of the steroid-base linkage could rather be explained via the formation of an ion-dipole complex accompanied by a deuterium transfer from the OD group of the catechol to the neutral base moiety of such a complex as presented in Scheme 4.

\section{Conclusion}

In this study, the use of deuterated 2-hydroxyestradiol allowed the differentiation of isomeric adducts using LC-ESI-MS ${ }^{\mathrm{n}}$. The study of the $\mathrm{m} / z$ shift as well as the fragmentation pathways observed for the quasi-molecular ions have shown that addition of the base could occur on both the C6 and C9 sites of the steroid B ring in its quinone-methide form. Although compounds attributed to the degradation of an adduct formed by nucleophilic attack of the base on C9 position have already been identified [39, 42, 43], the corresponding adducts had never been clearly evidenced by LC-MS ${ }^{\mathrm{n}}$ until this work. Some complementary work needs now to be developed in order (1) to achieve a complete chromatographic separation of the $\mathrm{C} 6$ and $\mathrm{C} 9$ adducts which coelute in our LC-MS experiments and (2) to improve the understanding of the particular fragmentation process of this adduct.

\section{Acknowledgments}

The authors thank Huguette Petit for his excellent technical assistance in the syntheses of deuterated compounds, and Christel Van Aerden for preliminary works on this topic.

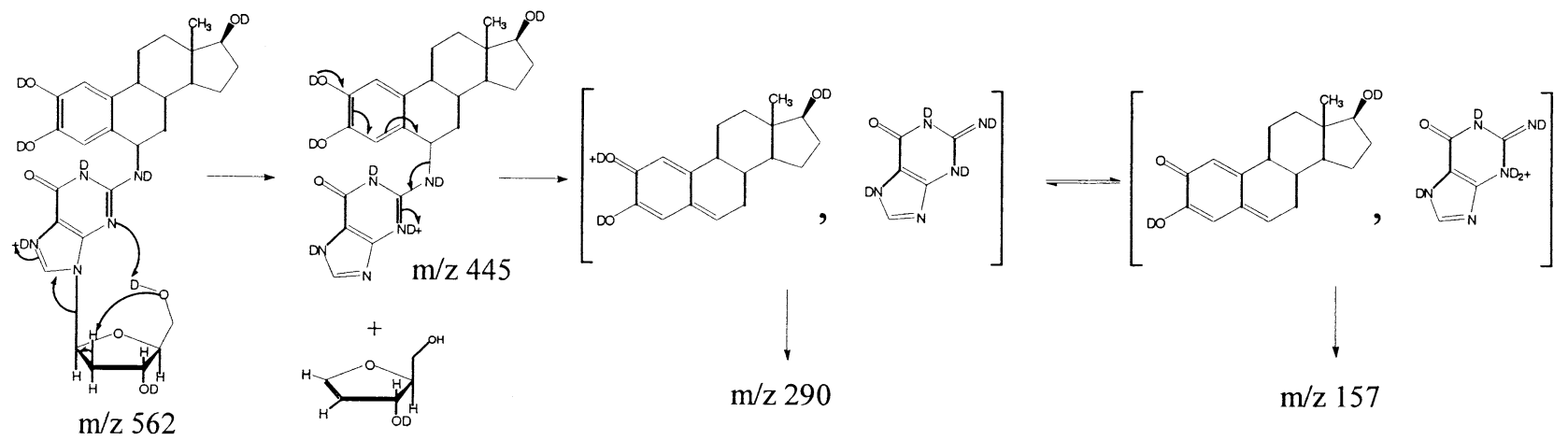

Scheme 4. Proposed mechanism for the fragmentation of the $\left[\mathrm{M}_{\mathrm{d} 7}+\mathrm{D}\right]^{+}$ion of $2-\mathrm{OHE}_{2}-6-\mathrm{N}^{2}-\mathrm{dG}$ under $\mathrm{MS}^{\mathrm{n}}$ conditions. 


\section{References}

1. Cavalieri, E.; Frenkel, K.; Liehr, J. G.; Rogan, E.; Roy, D. Estrogens as Endogenous Genotoxic Agents-DNA Adducts and Mutations. J. Natl. Cancer Inst. Monogr. 2000, 27, 75-93.

2. Bolton, J. L.; Pisha, E.; Zhang, F.; Qiu, S. Role of Quinoids in Estrogen Carcinogenesis. Chem. Res. Toxicol. 1998, 11, 11131127.

3. Zhu, B. T.; Conney, A. H. Functional Role of Estrogen Metabolism in Target Cells: Review and Perspectives. Carcinogenesis 1998, 19, 1-27.

4. Butterworth, M.; Lau, S. S.; Monks, T. J. 17 $\beta$-Estradiol Metabolism by Hamster Hepatic Microsomes: Comparison of Catechol EstrogenO-Methylation with Catechol Estrogen Oxidation and Glutathione Conjugation. Chem. Res. Toxicol. 1996, 9, 793-799.

5. Rathahao, E; Hillenweck, A.; Paris, A.; Debrauwer, L. Investigation of the in Vitro Metabolism of $17 \beta$-Estradiol by LCMS/MS Using ESI and APCI. Analysis 2000, 28, 273-279.

6. Abul-Hajj, Y. J.; Tabakovic, K.; Gleason, W. B.; Ojala, W. H. Reactions of 3,4-Estrone Quinone with Mimics of Amino Acid Side Chains. Chem. Res. Toxicol. 1996, 9, 434-438.

7. Dwivedy, I.; Devanesan, P.; Cremonesi, P.; Rogan, E.; Cavalieri, E. L. Synthesis and Characterization of Estrogen 2,3- and 3,4-Quinones. Comparison of DNA Adducts Formed by the Quinones Versus Horseradish Peroxidase-Activated Catechol Estrogens. Chem. Res. Toxicol. 1992, 5, 828-833.

8. Stack, D. E.; Byun, J.; Gross, M. L.; Rogan, E. G.; Cavalieri, E. L. Molecular Characteristics of Catechol Estrogen Quinones in Reactions with Deoxyribonucleosides. Chem. Res. Toxicol. 1996, 9, 851-859.

9. Terashima, I.; Suzuki, N.; Shibutani, S. Mutagenic Properties of Estrogen Quinone-Derived DNA Adducts in Simian Kidney Cells. Biochemistry 2001, 40, 166-172.

10. Chakravarti, D.; Mailander, P. C.; Li, K. M.; Higginbotham, S.; Zhang, H. L.; Gross, M. L.; Meza, J. L.; Cavalieri, E. L.; Rogan, E. G. Evidence that a Burst of DNA Depurination in SENCAR Mouse Skin Induces Error-Prone Repair and Forms Mutations in the H-ras Gene. Oncogene 2001, 20, 7945-7953.

11. Cao, K.; Stack, D. E.; Ramanathan, R.; Gross, M. L.; Rogan, E. G.; Cavalieri, E. L. Synthesis and Structure Elucidation of Estrogen Quinones Conjugated with Cysteine, N-Acetylcysteine, and Glutathione. Chem. Res. Toxicol. 1998, 11, 909-916.

12. Cao, K.; Devanesan, P.; Ramanathan, R.; Gross, M. L.; Rogan, E. G.; Cavalieri, E. L. Covalent Binding of Catechol Estrogens to Glutathione Catalyzed by Horseradish Peroxidase, Lactoperoxidase, or Rat Liver Microsomes. Chem. Res. Toxicol. 1998, 11, 917-924.

13. Ramanathan, R.; Cao, K.; Cavalieri, E. L.; Gross, M. L. Mass Spectrometric Methods for Distinguishing Structural Isomers of Glutathione Conjugates of Estrone and Estradiol. J. Am. Soc. Mass Spectrom. 1998, 9, 612-619.

14. Abul-Hajj, Y. J.; Tabakovic, K.; Tabakovic, I. An EstrogenNucleic Acid Adduct. Electroreductive Intermolecular Coupling of 3,4-Estrone-o-Quinone and Adenine. J. Am. Chem. Soc. 1995, 117, 6144-6145.

15. Akanni, A.; Tabakovic, K.; Abul-Hajj, Y. J. Estrogen-Nucleic Acid Adducts: Reaction of 3,4-Estrone-o-Quinone with $\mathrm{Nu}$ cleic Acid Bases. Chem. Res. Toxicol. 1997, 10, 477-481.

16. Akanni, A.; Abul-Hajj, Y. J. Estrogen-Nucleic Acid Adducts: Reaction of 3,4-Estrone-o-Quinone Radical Anion with Deoxyribonucleosides. Chem. Res. Toxicol. 1997, 10, 760-766.

17. Cavalieri, E. L.; Stack, D. E.; Devanesan, P. D.; Todorovic, R.; Dwivedy, I.; Higginbotham, S.; Johansson, S. L.; Patil, K. D.; Gross, M. L.; Gooden, J. K.; Ramanathan, R.; Cerny, R. L.; Rogan, E. G. Molecular Origin of Cancer: Catechol Estrogen3,4-Quinones as Endogeneous Tumor Initiators. Proc. Natl. Acad. Sci. U.S.A. 1997, 94, 10937-10942.
18. Devanesan, P.; Todorovic, R.; Zhao, J.; Gross, M. L.; Rogan, E. G.; Cavalieri, E. L. Catechol Estrogen Conjugates and DNA Adducts in the Kidney of Male Syrian Golden Hamsters Treated with 4-Hydroxyestradiol: Potential Biomarkers for Estrogen-Initiated Cancer. Carcinogenesis 2001, 22, 489-497.

19. Zeisig, M.; Möller, L. 32P-Postlabeling High-Performance Liquid Chromatographic Improvements to Characterize DNA Adduct Stereoisomers from Benzo[a]pyrene and Benzo[c]phenanthrene, and to Separate DNA Adducts from 7,12Dimethylbenz[a]anthracene. J. Chromatogr. B 1997, 691, 341350 .

20. Farmer, P. B.; Sweetman, G. M. A. Mass Spectrometric Detection of Carcinogen Adducts. J. Mass Spectrom. 1995, 30, 1369 1379.

21. Chaudhary, A. J.; Nokubo, M.; Oglesby, T. D.; Marnett, L. J.; Blair, I. A. Characterization of Endogeneous DNA Adducts by Liquid Chromatography/Electrospray Ionization Tandem Mass Spectrometry. J. Mass Spectrom. 1995, 30, 1157-1166.

22. Chiarelli, M. P.; Lay, J. O. Mass Spectrometry for the Analysis of Carcinogen-DNA Adducts. Mass Spectrom. Rev. 1992, 11, 447-493.

23. Esmans, E. L.; Broes, D.; Hoes, I.; Lemière, F.; Vanhoutte, K. Liquid Chromatography-Mass Spectrometry in Nucleoside, Nucleotide, and Modified Nucleotide Characterization. J. Chromatogr. A 1998, 794, 109-127.

24. Andrews, C. L.; Vouros, P.; Harsh, A. Analysis of DNA Adducts Using High-Performance Separation Techniques Coupled to Electrospray Ionization Mass Spectrometry. J. Chromatogr. A 1999, 856, 515-526.

25. Apruzzese, W. A.; Vouros, P. Analysis of DNA Adducts by Capillary Methods Coupled to Mass Spectrometry: A Perspective. J. Chromatogr. A 1998, 794, 97-108.

26. McLuckey, S. A.; Van Berkel, G. J.; Glish, G. L. Tandem Mass Spectrometry of Small, Multiply Charged Oligonucleotides. J. Am. Soc. Mass Spectrom. 1992, 3, 60-70.

27. Wang, Y.; Taylor, J.; Gross, M. L. Fragmentation of Electrospray-Produced Oligonucleotide Ions Adducted to Metal Ions. J. Am. Soc. Mass Spectrom. 2001, 12, 550-556.

28. McLuckey, S. A.; Habibi-Goudarzi, S. Ion Trap Tandem Mass Spectrometry Applied to Small Multiply Charged Oligonucleotides with a Modified Base. J. Am. Soc. Mass Spectrom. 1994, 5, 740-747.

29. Marzilli, L. A.; Wang, D.; Kobertz, W. R.; Essigmann, J. M.; Vouros, P. Mass Spectral Identification and Positional Mapping of Aflatoxin $\mathrm{B}_{1}$-Guanine Adducts in Oligonucleotides. J. Am. Soc. Mass Spectrom. 1998, 9, 676-682.

30. Wang, Y.; Taylor, J. S.; Gross, M. L. Fragmentation of Photomodified Oligonucleotides Adducted with Metal Ions in an Electrospray Ionization Ion Trap Mass Spectrometer. J. Am. Soc. Mass Spectrom. 2001, 12, 1174-1179.

31. Ding, J.; Barlow, T.; Dipple, A.; Vouros, P. Separation and Identification of Positively Charged and Neutral Nucleoside Adducts by Capillary Electrochromatography-Microelectrospray Mass Spectrometry. J. Am. Soc. Mass Spectrom. 1998, 9, 823-829.

32. Kambouris, S. J.; Chaudhary, A. K.; Blair, I. A. Liquid Chromatography/Electrospray Ionization Tandem Mass Spectroscopy (LC/ESI/MS/MS) Analysis of 1,2-Epoxybutene Adducts of Purine Deoxynucleosides. Toxicology 1996, 113, 331-335.

33. Hoes, I.; Lemière, F.; Van Dongen, W.; Vanhoutte, F.; Esmans, E. L.; Bockstaele, D. V.; Berneman, Z.; Deforce, D. Van den; Eeckhout, E. G. Analysis of Melphalan Adducts of 2'-Deoxynucleotides in Calf Thymus DNA Hydrolysates by Capillary High-Performance Liquid Chromatography-Electrospray Tandem Mass Spectrometry. J. Chromatogr. B 1999, 736, 43-59. 
34. Van Aerden, C.; Debrauwer, L.; Tabet, J. C.; Paris, A. Analysis of Nucleoside-Estrogen Adducts by LC-ESI-MS-MS. Analyst 1998, 123, 2677-2680.

35. Convert, O.; Van Aerden, C.; Debrauwer, L.; Rathahao, E.; Molines, H.; Fournier, F.; Paris, A. Reactions of Estradiol-2,3Quinones with Deoxynucleosides: Possibles Insights in the Reactivity of Estrogen Quinones with DNA. Chem. Res. Toxicol. 2002, 15, 754-764.

36. Gelbke, H. P.; Haupt, O.; Knuppen, R. A Simple Chemical Method for the Synthesis of Catechol Estrogens. Steroids 1976, 21, 205-218.

37. Abul-Hajj, Y. J. Synthesis of 3,4-Estrogen-o-Quinone. J. Steroid Biochem. 1984, 21, 621-622.

38. Garza, G. A.; Rao, P. N. Chromic Anhydride-3,5-Dimethylpyrazole Complex: An Efficient Reagent for Oxidation of Steroidal Estrogens to 6-Oxo-Derivatives. Steroids 1983, 42, 469-474.

39. Iverson, S. L.; Hu, L. Q.; Vukomanovic, V.; Bolton, J. L. The Influence of thep-Alkyl Substituent on the Isomerization ofo-
Quinones top-Quinone Methides: Potential Bioactivation Mechanisms for Catechols. Chem. Res. Toxicol. 1995, 8, 537-544.

40. Bolton, J. L.; Shen, L. p-Quinone Methides are the Major Decomposition Products of Catechol Estrogen o-Quinones. Carcinogenesis 1996, 17, 925-929.

41. Bolton, J. L.; Wu, H. M.; Hu, L. Q. Mechanism of Isomerization of 4-Propyl-o-Quinone to its Tautomeric $p$-Quinone Methide. Chem. Res. Toxicol. 1996, 9, 109-113.

42. Iverson, S. L.; Shen, L.; Anlar, N.; Bolton, J. L. Bioactivation of Estrone and its Catechol Metabolites to Quinoid-Glutathione Conjugates in Rat Liver Microsomes. Chem. Res. Toxicol. 1996, 9, 492-499.

43. Van Aerden, C.; Debrauwer, L.; Fournier, F.; Rathahao, E.; Convert, O.; Molines, H.; Paris, A.; Tabet, J. C. Investigation of the Reaction of Estradiol-2,3-Quinone and Deoxyribonucleosides Using LC-ESI-MS ${ }^{n}$. Proceeding of the 46th ASMS Conference on Mass Spectrometry and Allied Topics; Long Beach, CA, June 2000, p 103. 